\title{
Research of Battery Protection System based on Voltage Comparator
}

\author{
Haidong Zou ${ }^{1, a^{*}}$, Ning Dong ${ }^{1, b}$ and Xiaojun $\mathrm{He}^{1, \mathrm{c}}$ \\ ${ }^{1}$ China Satellite Maritime Tracking and Control Department, Jiangsu, China \\ acnflyfish@foxmail.com, b993716469@qq.com, ‘429851047@qq.com
}

Keywords: Lead-acid battery; Voltage comparator; Alarm circuit

\begin{abstract}
Aiming at the problem of low-voltage protection of power supply in lead-acid battery system, a battery protection system based on voltage comparator is proposed. The simulation results show that the design scheme is feasible and simple, which can realize the safety protection of lead-acid battery. The research provides a way to improve the information level of equipment maintenance.
\end{abstract}

\section{Introduction}

Lead-acid batteries have been widely used in aerospace systems, which can provide the equipment with high quality power supply, such as high ripple coefficient, steady voltage supply, etc. However, there lacks of monitoring means. There has been a problem in the battery system caused by lack of power supply protection, which will seriously affect its service life. In order to solve this problem, it is necessary to improve the maintenance of lead-acid batteries.

The design of the voltage protection system of lead-acid battery with integrated operational amplifier as core element control, which can automatic detect the voltage of the battery in real-time. The system can control and alarm with output protection, which overcomes the defects of the existing device. This paper can simplify the circuit structure of the design, improve the reliability of the lead-acid battery system. The biggest characteristic of voltage protection system designed in this paper is the voltage range, agree with almost all battery systems used in the system with quick and timely response. Thus the design can realize the protection of lead-acid battery equipment.

\section{Circuit Design Based on Voltage Comparator}

General integrated operational amplifier in the open loop or positive feedback, the work in the nonlinear region, which can form a single or window voltage comparator. The voltage comparator is an analog voltage signal input circuit and the threshold voltage is compared after output limit or negative limit, mainly used for waveform generation and conversion, conversion of voltage amplitude identification, waveform shaping and analog signal and digital signal field.

Design of Voltage Comparator. For lead-acid batteries, the usual working voltage is $+12 \mathrm{~V},+24 \mathrm{~V}$, $+36 \mathrm{~V}$ and $+48 \mathrm{~V}$, etc.. The working voltage of lead-acid battery in the system is $+24 \mathrm{~V}$. Then the design of the voltage protection system, the need to design a single voltage can be compared.

Fig. 1 shows the voltage comparator designed for this system. The reference voltage $\mathrm{Vr}$ is connected to the in-phase end of the operational amplifier, and the input voltage (the output voltage end of the battery is detected) is connected to the inverting terminal of the operational amplifier, and the output end of the Vo is connected with a voltage stabilizing tube Dz as the output voltage of the protection circuit. When the input voltage $\mathrm{Vi}<\mathrm{Vr}$, indicating that the battery operating voltage is too low, then the op amp output high voltage, stable reverse voltage regulator $\mathrm{Dz}$, the output voltage $\mathrm{V}$. It is clamped to its stable voltage $\mathrm{Vz}$, i.e. $\mathrm{Vo}=\mathrm{Vz}$. When the input voltage $\mathrm{Vi}>\mathrm{Vr}$, indicating that the battery operating voltage is normal, this time the op amp output voltage, voltage regulator Dz positive conduction, the output voltage $\mathrm{V}$. Equal to the forward voltage regulator voltage $\mathrm{Vd}$, or $\mathrm{Vo}=-\mathrm{Vd}$. The circuit transmission characteristics are shown in Fig. 2. 


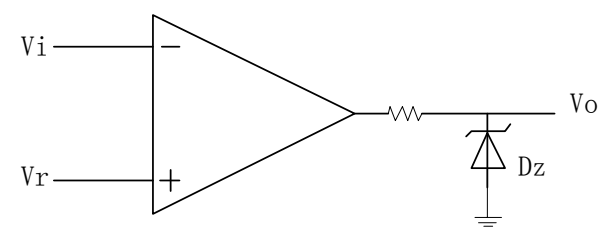

Figure 1. Chart of voltage comparator

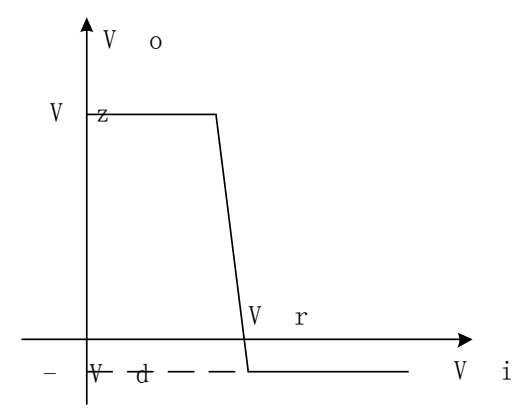

Figure 2. Output of voltage comparatore

Design of Alarm Protection Circuit. For the existing battery system, it is necessary to design the alarm protection circuit. According to the voltage comparator circuit in front of the design, when the output of high level Vz, said the battery has been under pressure to run, and cut off the output will give an alarm, in order to facilitate the timely disposal of operating personnel.

The alarm protection circuit is shown in Fig. 3. The system needs to access a NPN type transistor Q, a sound and light alarm Beep and a response relay $\mathrm{J}$. The current voltage comparator output voltage is less than Vo of the triode Q turn-on voltage, then the transistor Q is switched off, the collector is to maintain a high level, then the acousto-optic alarm and relay are not working, then said battery system is working properly. The current voltage comparator output voltage is greater than the Vo of the triode Q turn-on voltage, then the triode $\mathrm{Q}$ is conducted, the collector and emitter level is flat, sound and light alarm and relay work means the battery system work abnormally. When the relay is operated, the output voltage of the battery can be cut off in time, so as to realize the protection of the voltage of the accumulator.

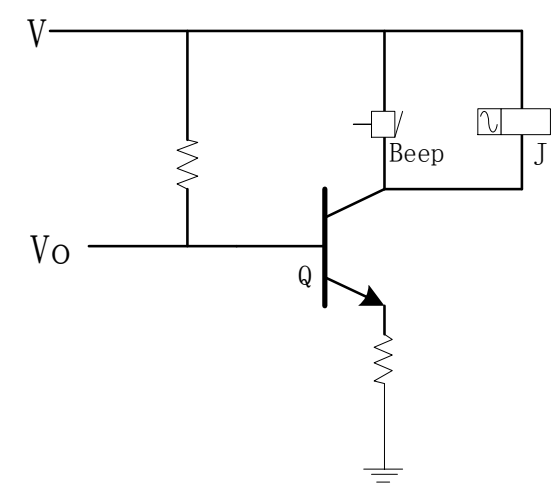

Figure 3. Chart of alarm circuit

\section{System Simulation}

In order to verify the design effect of the system, the simulation experiment is carried out in MultiSim. By using the MultiSim (DC Sweep) function, the voltage transfer characteristics between the input and output of the voltage comparator can be simulated. First of all, in the MultiSim in front of the model built to draw, the effect is shown in figure 3. Reference power supply for operational amplifier noninverting terminal access to $13.8 \mathrm{~V}$. Because my ship $+24 \mathrm{~V}$ lead acid battery protection voltage is $+12 \mathrm{~V}$, the design of reserve $15 \%$ of the margin, it is concluded that the results of $13.8 \mathrm{~V}$. The inverting terminal of the operational amplifier is connected with a scanning DC power supply, and the voltage range is from $+24 \mathrm{~V}$ to $+10 \mathrm{~V}$ to simulate the actual discharge effect of the battery. The simulation results are shown in Fig. 4. 


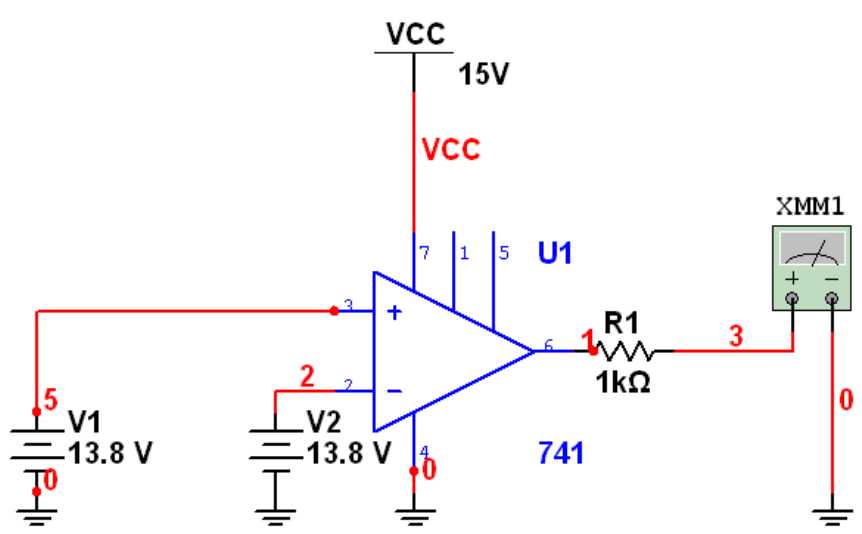

Figure 4. Results of model simulation

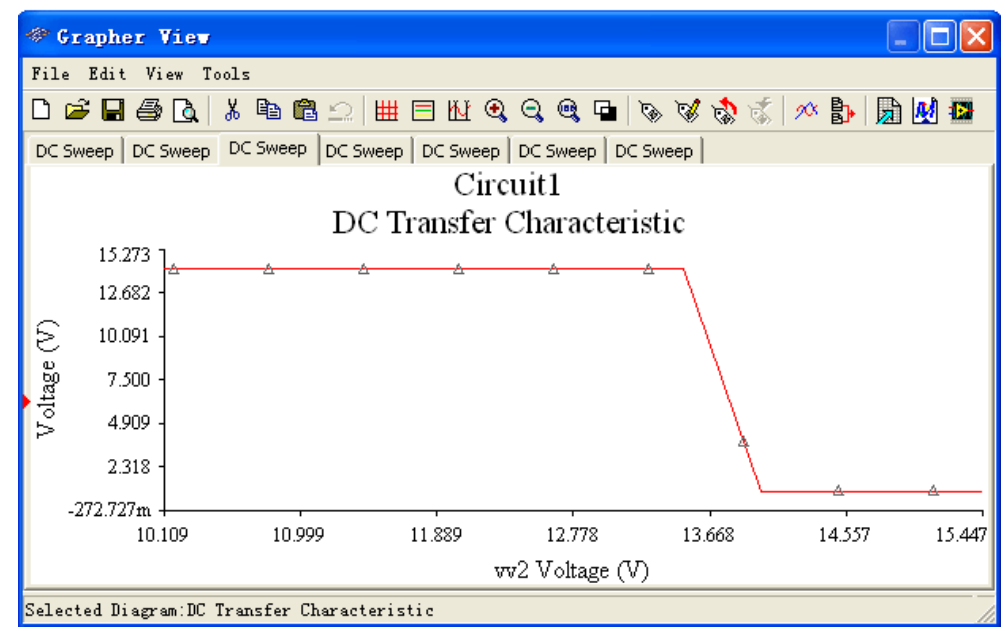

Figure 5. Results of system simulation

The result shows that when the battery output voltage is lower than $+13.8 \mathrm{~V}$, the operational amplifier outputs a high level at the same time, alarm and protection circuit connected to the operational amplifier after the start, realize the safety protection of the battery, when the battery voltage up to $+13.8 \mathrm{~V}$ or more, then the operational amplifier output low level alarm and protection circuit are reset.

\section{Conclusions}

This combination of lead-acid battery can lead to the lack of safety protection under pressure operation, affect the service life of the problem, combined with the design of operational amplifier voltage comparator and subsequent alarm and protection circuit, the function is perfect. The simulation results show that the circuit designed in this paper is reliable, effective and simple. The function of the circuit will be studied in order to establish the remote monitoring system and improve the information level of equipment maintenance.

\section{References}

[1] ZOU Hai-dong, QIAN Liang. Research on parameter acquisition system of telecommunication source, Electronic Design Engineering, 2012.09(17):101-103.

[2] LI Qi, YANG Xin. Journal of Chifeng University(Natural Science Edition),2013.08(29):35-37.

[3] ZHANG Yin-feng, NIE Zi-ling, etc. $\mu$ Analysis and Synthesis Method for Aviation Power Supply. Power Electronics, 2016.12(50):102-105. 
[4] LIU Ji-wen, WANG Jian-xiong,etc. Research of Dual-CAN bus in mine IOT communication power monitoring system. Chinese Journal of Power Sources, 2016.12(40):2461-2462.

[5] ZHAO Xu-cheng1, WANG Xu-kun,etc. Led-acid battery performance testing research based on neural network technology. Chinese Journal of Power Sources, 2016.12(40):2405-2406.

[6] ZHANG Qing-wei, WU Yu-zhu, FENG Yi. Research of Protection Method for Substation Battery Open Circuit. Journal of Jiangxi Vocational and Technical College of Electricity, 2016.03(29):5-10.

[7] LI Xiao-wei,ZHAO Hai-fa. Design and Production of Temperature and Humidity Controller Based on the LM324 Voltage Comparator. Value Engineering, 2016.11(35):143-144.

[8] Robert L. Boylestad \& Louis Nashelsky. Electronic Devices and Circuit Theory .2012.04. 